DOI:

\title{
ЕКСПЕРТНА СИСТЕМА ДЛЯ ДІАГНОСТУВАННЯ ГЕНЕТИЧНИХ ВІДХИЛЕНЬ
}

\author{
В. 3. Стецюк, Л. Ю. Бабінцева ${ }^{1}$, Ю. М. Чиж, \\ Національний технічний університет України \\ «Київський політехнічний інститут імені Ігоря Сікорського» \\ ${ }^{1}$ Національна медична академія післядипломної освіти імені П. Л. Шупика \\ Національна дитяча спеціалізована лікарня «ОХМАТДИТ»
} О. Д. Фіногенов, Н. В. Самоненко

У статті описано експертну систему «Експертна система для діагностування генетичних відхилень», створену для покращення процесу встановлення діагнозу за рахунок зменшення ймовірності лікарської помилки при діагностуванні захворювання, ведення обліку та реєстрації пацієнтів із спадковими порушеннями метаболізму. Система призначена на допомогу працівникам відділення медичної генетики.

Ключові слова: експертна система, база знань, відділення медичної генетики, реєстр спадкових порушень метаболізму.

\section{EXPERT SYSTEM FOR DIAGNOSING GENETIC DISORDERS}

\section{Z. Stetsyuk, L. Yu. Babintseva ${ }^{1}$, Yu. M. Chyzh, O. D. Finogenov, N. V. Samonenko}

National Technical University of Ukraine «Igor Sikorsky Kyiv Polytechnic Institute» ${ }^{1}$ Shupyk National Medical Academy of Postgraduate Education National Children's Hospital «OKHMATDYT»

Background. Expert systems are a class of computer programs that offer advice, analyze, classify, advise, and diagnose. After studying and analyzing the problems of the field of genetics, we decided to develop an expert system, which with the help of the available knowledge base will be able to determine and clarify the diagnosis, provide advice and, if necessary, appoint additional examinations.

The purpose of this work is to develop a computer software «Expert system for diagnosing genetic disorders».

Materials and methods. The research material is the work of a geneticist who diagnoses and prescribes treatment to patients, maintains medical records.

Results. The result of the research of the work of employees of the department of medical genetics of Children's Hospital and the analysis of the specifics of the implementation of medical expert systems is an expert system that optimizes the work of department staff.

The software product «Expert system for diagnosing genetic disorders» is installed on any number of computers in the department.

The system implements the following functions:

- work in two modes: the mode of knowledge acquisition and the mode of consultation;

- establishing the correspondence of symptoms, further treatment and diagnoses in the mode of acquiring knowledge;

- diagnosis of the patient when choosing symptoms from a list;

- providing referrals for clinical trials to clarify the diagnosis;

- providing a treatment protocol for the diagnosis;

- registration of patients and results of inspections depending on the established diagnosis

- dynamic management of the presence of the required diagnosis;

- formation of reporting for the specified periods with the ability to view and print information on certain indicators;

- visualization of the results of statistical analysis using diagrams of different types.

Conclusions. The main result of the work is a system that optimizes the work of doctors and staff of the department of medical genetics of Children's Hospital.

Key words: expert system, knowledge base, department of medical genetics, register of hereditary metabolic disorders. 


\title{
ЭКСПЕРТНАЯ СИСТЕМА ДЛЯ ДИАГНОСТИКИ ГЕНЕТИЧЕСКИХ НАРУШЕНИЙ
}

\author{
В. З. Стецюк, Л. Ю. Бабинцева ${ }^{1}$, Ю. М. Чиж, \\ О. Д. Финогенов, Н. В. Самоненко \\ Национальный технический университет Украины \\ «Киевский политехнический институт им. Игоря Сикорского» \\ ${ }^{1}$ Национальная медицинская академия последипломного образования имени П. Л. Шупика \\ Национальная детская специализированная больница «ОХМАТДЕТ»
}

В статье описана экспертная система «Экспертная система для диагностики генетических отклонений», созданная для улучшения процесса установления диагноза, уменьшения вероятности врачебной ошибки при диагностировании заболеваний, ведения учета и регистрации пациентов с наследственными нарушениями метаболизма. Система предназначена для облегчения работы сотрудников отделения медицинской генетики.

Ключевые слова: экспертная система, база знаний, отделение медицинской генетики, реестр наследственных нарушений метаболизма. 
Вступ. Експертні системи - це клас комп'ютерних програм, що пропонують рекомендації, проводять аналіз, виконують класифікацію, надають консультації і ставлять діагноз. Вони орієнтовані на розв'язування завдань, вирішення яких вимагає проведення експертизи людиноюспеціалістом. На відміну від програм, що використовують процедурний аналіз, експертні системи розв'язують проблеми у вузькій предметній площині (конкретній ділянці експертизи) на основі логічних міркувань. Такі системи часто можуть знайти розв'язок неструктурованих і неточно визначених завдань. Через використання евристик вони компенсують відсутність структурованості, що корисно в ситуаціях, коли недостатня кількість необхідних даних або часу виключає можливість проведення повного аналізу.

Відомо, що основою експертної системи (ЕС) $€$ сукупність знань, яка структурується для спрощення процесу прийняття рішення. Для спеціалістів у галузі штучного інтелекту термін «знання», як правило, означає інформацію, яка потрібна програмі для того, щоб вона виконувала інтелектуальний процес. Ця інформація приймає форму фактів або правил. На жаль, факти та правила не завжди правдиві або неправильні, інколи існує деяка міра неправильності в достовірності факту або точності правила. Якщо сумнів виражається явно, то він називається коефіцієнтом упевненості.

Після вивчення проблематики сфери діяльності професії лікаря-генетика виникла ідея створення такого комп'ютерного програмного комплексу, що за допомогою наявної бази знань зможе визначати та уточнювати діагноз, надавати консультації та, у разі необхідності, призначати додаткові обстеження. Реалізація даної експертної системи здійснюється на базі вже впровадженої програми «Реєстр спадкових порушень метаболізму» [1], що забезпечує автоматизацію та спрощення процесу обліку і реєстрації пацієнтів із спадковими порушеннями метаболізму. Програмний продукт передбачає покращення роботи лікаря-лаборанта; створення всеукраїнського реєстру спадкових порушень метаболізму; зменшення ймовірності втрат даних про надходження нових пацієнтів; можливість вчасно направити пацієнта на лікування.

Головною перевагою впровадження системи $\epsilon$ зменшення часу на встановлення діагнозу, що в свою чергу пришвидшує настання початку лікування пацієнта. Крім цього, завдяки даному програмному комплексу зменшується час на рутинну роботу з медичною документацією та оформлення надходження на лікування нового пацієнта, що в свою чергу збільшує час для роботи з результатами обстежень, відповідно покращується точність та якість рішення, яке приймається.

Очевидною видається й актуальність даної роботи, пов'язана з розробленням дієвого інструменту у вигляді комп'ютерної системи, що забезпечує контроль над встановленим лікарем діагнозом і зменшення ймовірності лікарської помилки при діагностуванні захворювання, обробку облікової медичної документації про пацієнтів із спадковими порушеннями метаболізму.

Мета роботи: створення комп'ютерного програмного комплексу «Експертна система для діагностування генетичних відхилень», що призначений на допомогу лікареві при встановленні діагнозу (в тому числі, виконання функцій контролю та консультування), а також для функцій медичного документообігу, звітності та статистики: облік та реєстрація пацієнтів зі спадковими порушеннями метаболізму, основної інформації про кожного пацієнта, формування звітності тощо.

Матеріали та методи дослідження. Для розробки даного програмного продукту використовувалась мова програмування $\mathrm{C}++$ та середовище програмування Embarcadero C++ Builder XE7. Для збереження даних розроблено відповідну реляційну локальну базу даних формату SQL Server. Для реалізації роботи з базою даних обрано Microsoft SQL Server 2012 Express. Матеріалом дослідження стала робота лікаря-генетика, який встановлює діагноз і призначає пацієнтам лікування, веде лікарську документацію. Тобто в основу системи покладено базу даних електронної медичної облікової документації відділення медичної генетики дитячої лікарні «ОХМАТДИТ», способи ії оброблення та формування результату за визначеними параметрами.

Результати та їх обговорення. В результаті дослідження роботи працівників відділення медичної генетики дитячої лікарні та аналізу специфіки реалізації медичних експертних систем постало завдання створення експертної системи, що оптимізує роботу медичного персоналу відділення. Ще одним із завдань дослідження було визначення можливостей застосування бази даних медичної документації для обліку та реєстрації пацієнтів зі спадковими порушеннями метаболізму з метою отримання результуючого діагнозу за наявними симптомами, оперативної та періодичної статистичної звітності. 
У роботі створеної експертної системи виділено два основні режими: режим набуття знань і режим вирішення завдання (у тому числі, режим консультації або режим використання).

У режимі набуття знань спілкування з експертною системою здійснює експерт (за допомогою інженера знань, у нашому випадку це лікар, який встановлює діагноз і призначає лікування пацієнтам). Використовуючи компонент набуття знань, експерт описує проблемну галузь у вигляді сукупності фактів і правил. Іншими словами, «наповнює» експертну систему знаннями, що дозволяють у подальшому їй самостійно вирішувати завдання 3 проблемної галузі. Експертом вважали користувача системи, який задає відповідність симптоматики та діагнозів. Зазначимо, що цьому режиму при традиційному підході до програмування відповідають такі етапи: алгоритмізації, програмування та налагодження. Отже, на відміну від традиційного підходу у випадку експертних систем розроблення програми здійснює не програміст, а експерт, який не володіє навиками програмуванням.

У режимі консультацій спілкування з експертною системою здійснює кінцевий користувач, якого цікавить результат або спосіб його одержання. Необхідно відзначити, що залежно від призначення експертної системи користувач може:

- не бути спеціалістом у даній предметній галузі, і в цьому випадку він звертається до експертної системи за результатом, що не вміє отримати сам;

- бути спеціалістом, і в цьому випадку він зверта- ється до експертної системи з метою прискорення отримання результату, покладаючи на експертну систему рутинну роботу.

Слід зазначити, що на відміну від традиційних програм, експертні системи при вирішенні завдання не тільки виконують прописану алгоритмом послідовність операцій, але і самі попередньо формують і1. Добре побудована експертна система має можливість самонавчатися на розв'язуваних завданнях, поповнюючи автоматично свою базу знань результатами отриманих висновків і рішень.

Існує ще одна важлива відмінність експертних систем від традиційних програм. Якщо звичайні програми розробляються так, щоб кожен раз отримувати правильний результат, то ЕС розроблені, щоб поводитися як експерти. Вони, як правило, дають правильні відповіді, але іноді, як і люди, здатні помилятися.

При вирішенні складних завдань традиційні програми також можуть робити помилки. Проте ï дуже важко виправити, оскільки алгоритми, що лежать у їх основі, явно в них не сформульовані. $\mathrm{EC}$, подібно людям, мають потенційну можливість учитися на своїх помилках.

Програмний продукт «Експертна система для діагностування генетичних відхилень» (рис. 1) встановлюється на одному комп'ютері відділення медичної генетики. Оператором даної програми $\epsilon$ лікар, який проводить огляд, консультації та лікування пацієнтів. Ця прикладна програма передбачає отримання медичної та статистичної звітності.

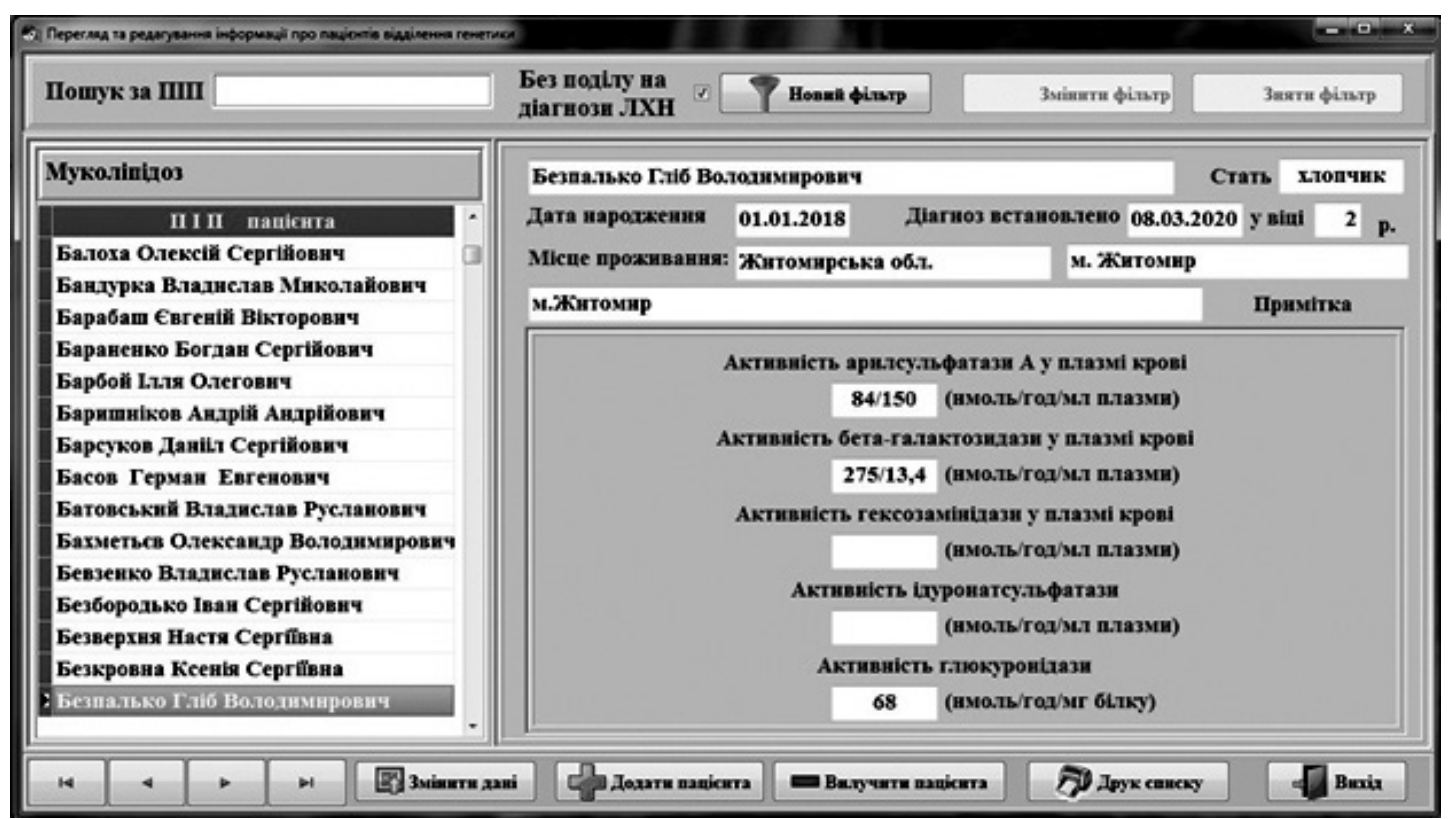

Рис. 1. Експертна система для діагностування генетичних відхилень 
Система реалізує такі функції:

- робота у двох режимах: режим набуття знань i режим консультації;

- встановлення відповідності симптоматики, подальшого лікування і діагнозів у режимі набуття знань;

- встановлення діагнозу пацієнта при виборі симптомів із певного переліку;

- надання направлень на клінічні дослідження 3 метою уточнення діагнозу;

- надання протоколу лікування за встановленим діагнозом;

- облік пацієнтів і результатів обстежень у залежності від встановленого діагнозу;
- фільтрація пацієнтів за обраними критеріями;

- збереження основної інформації про кожного пацієнта;

- автоматичне відображення списку показників обстежень у залежності від обраного діагнозу захворювання;

- динамічне управління наявністю необхідного діагнозу;

- формування звітності за вказані періоди з можливістю перегляду та друку інформації за певними показниками (рис. 2);

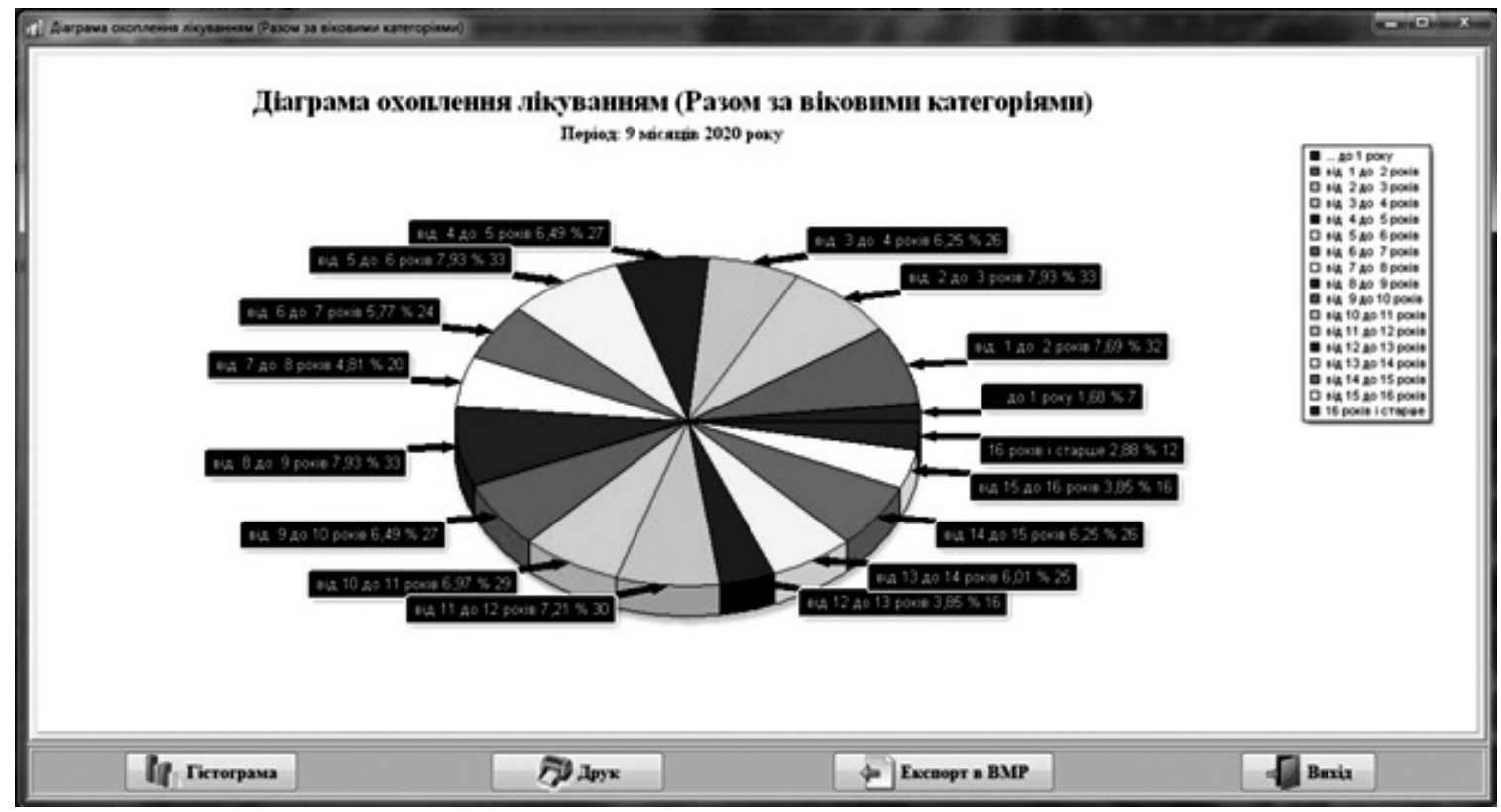

Рис. 2. Формування звітності за визначені періоди

- візуалізація результатів статистичного аналізу

iз застосуванням діаграм різного виду.

Користувач програми може виконувати такі дії:

- створення/видалення/редагування запису про пацієнта;

- перегляд відомостей по кожному пацієнту;

- перегляд відомостей по кожному захворюванню;

- пошук пацієнта за його П.І.П/б. чи його частиною;

- фільтрація інформації про пацієнта за обраними критеріями (стать, діагноз, регіон проживання, вік, дата встановлення діагнозу);

- створення/видалення/редагування даних про діагноз;
- створення/видалення нової адміністративної одиниці;

- отримання контекстної довідки до будь-якого режиму програми;

- друк відомостей.

Висновки. Створено програмний продукт «Експертна система для діагностування генетичних відхилень», що призначений для покращення роботи лікаря за рахунок зменшення ймовірності лікарської помилки при діагностуванні захворювання. Також система забезпечує оптимізацію роботи всього персоналу відділення медичної генетики дитячої лікарні. 


\section{Література.}

1. Реєстр спадкових порушень метаболізму / В. 3. Стецюк, Л. Ю. Бабінцева, Т. П. Іванова, О. Ю. Барвінська, Ю. М. Чиж // Медична інформатика та інженерія. — 2018. — № 4. - С. 25-28.

2. Експертні системи в медицині : навч. посіб. для студентів вищих навчальних закладів / Синекоп Ю. С., Продеус А. М., Швець Є. Я. та ін. - Запоріжжя, 2014. - 332 с.

3. Документация по SQL Server. [Електронний ресурс]. — Режим доступу: https://goo.gl/VrWkUY.

4. Эккель Б. Философия С++. Введение в стандартный C++ / Эккель Брюс. - Санкт-Петербург: Питер, 2004. - 577 c.

5. Бьюли А. Изучаем SQL / Бьюли Алан. - СимволПлюс, 2009. - 312 с.

6. Программирование в C++ Builder / В. С. Романчик, А. Е. Люлькин. - Минск, 2007. - 128 с.

\section{References.}

1. Stetsyuk V. Z., Babintseva L. Yu. ... Chizh Yu. M. (2018). Register of hereditary metabolic disorders. Medical Informatics and Engineering, 4, 25-28.

2. Synekop Y. S., Prodeus A. M. ... Baran M. M. (2014). Expert systems in medicine: a textbook for students of higher educational institutions.

3. SQL Server Documentation. - [Electronic resource]. Access mode: https://goo.gl/VrWkUY.

4. Eckel B. (2000). Thinking in $\mathrm{C}++$, Volume One: Introduction to Standard C++ (2nd Edition). Prentice Hall.

5. Beaulieu A. (2009). Learning SQL. Second edition. O’Reilly Media, Inc.

6. Romanchik V. S., Lyulkin A. E. (2007). Programming in $C++$ Builder. Minsk. 